\title{
MULHERES, POLÍTICA E (SUB) REPRESENTAÇÃO FEMININA: A ADI 5617 E AS ACOOEES AFIRMATIVAS PARA ASSEGURAR A PARTICIPAÇAO FEMININA MÍNIMA NAS CASAS LEGISLATIVAS
}

\author{
WOMEN, POLITICS AND (SUB) FEMALE REPRESENTATION: \\ THE ADI 5617 AND THE AFFIRMATIVE ACTIONS TO ENSURE \\ MINIMUM FEMALE PARTICIPATION IN THE LEGISLATIVE \\ HOUSES \\ Felipe Magalhaes Bambirra ${ }^{1}$ \\ Milene de Souza Marques
}

\section{Recebido em: 13/05/2018 Aceito em: 30/09/2018 \\ fmbambirra@gmail.com milenesouzam1@gmail.com}

Resumo: No Brasil, foi apenas no século XX que as mulheres puderam, legalmente, votar e serem votadas, havendo este direito se consolidado, de modo definitivo, com a Constituição Federal de 1988. Contudo, o déficit representativo feminino continua acentuado: as mulheres ocupam menos de $12 \%$ dos das cadeiras dos parlamentos estaduais. Diante disto, o presente trabalho objetiva, a partir de uma metodologia crítico-propositiva, avaliar o atual cenário da participação feminina na política brasileira, considerando, em especial, as ações afirmativas promovidas e o julgamento da ADI 5617, adotando-se como hipótese a insuficiência do modelo de ação afirmativa existente, para, ao final, sugerir propostas capazes de, efetivamente, aumentar a representatividade feminina e diminuir este déficit democrático.

Palavras-chave: Direito Eleitoral. Mulheres na política. Igualdade de gênero na Política.

\begin{abstract}
In Brazil, it was only in the twentieth century that women were legally able to vote and to be voted. That right was only consolidated in a definitive way with the Federal constitution of 1988. However, the female representative deficit remains sharp: women occupy less than $12 \%$ of the chairs of the state parliaments. Considering this, the present article aims to evaluate the current scenario of female participation in Brazilian politics, considering, in particular, the affirmative actions promoted and the trial of ADI 5617, by a critical-propositive methodology. It was adopted, as hypothesis, the insufficiency of the existing affirmative action model. In conclusion, it was suggested actions that can be capable of effectively increasing female representativeness and, thus, decrease de democratic deficit.
\end{abstract}

Keywords: Electoral law. Women in politics. Gender equality in politics.

\section{INTRODUÇÃO}

As mulheres ocupam menos de $12 \%$ das vagas dos parlamentos estaduais e distrital brasileiro². Esse dado aponta, de modo claro, que as mulheres ainda não possuem uma posição de destaque no cenário político, dando lugar a uma grande sub-representação da população em referência ao seu gênero. Contudo, este dado não deve servir de suporte a mitos, como a apatia

\footnotetext{
${ }^{1}$ Universidade Federal de Goiás - Goiânia - Goiás - Brasil

${ }^{2}$ Dados disponíveis em: http://www.mpf.mp.br/pgr/noticias-pgr/proporcao-de-mulheres-na-politica-cresceuapenas-1-ponto-percentual-nas-ultimas-cinco-eleicoes Acesso em 06/11/2017.
} 
política ou desinteresse pelas coisas públicas por parte das mulheres. O problema central, entre outros, é a lógica de marginalização social (AVELAR, 2001, p. 16-7).

Atualmente, valoriza-se mais, do ponto de vista social, indivíduos que se destacam no mercado de trabalho, e, uma vez que as mulheres ainda não ocupam, de forma igualitária, os cargos e postos de direção laboral, a coletividade feminina acaba por não possuir o mesmo prestígio no imaginário coletivo. Segundo Avelar, as dificuldades encontradas pelas mulheres em função de sua condição não são decorrentes de sua situação individual, ou de deficiências particulares: as razões para a baixa representação feminina são de natureza estrutural. Em que pese a existência de toda a militância feminista pela igualdade na organização política, os ganhos ainda são poucos, uma vez que a conquista da igualdade formal não é a mesma da igualdade real, e a ampliação dos direitos de cidadania aos setores desprivilegiados é um processo lento(AVELAR, 2001, p. 16-7).

Bila Sorj (2005, p. 79-88) afirma que, a despeito das transformações das relações de gênero no último século - tais como a inserção da mulher no mercado de trabalho, exercício do voto, aumento da escolaridade etc. - certas desigualdades ainda não são percebidas como injustas, a exemplo da baixa participação feminina no parlamento. Embora exista um processo de mudança nas percepções sobre os gêneros, no sentido de uma cultura mais igualitária, as práticas sociais ainda são exercidas de forma bastante tradicional.

A respeito do assunto, Pamela Paxton, em sua obra intitulada "Women's Suffrage in the Measurement of Democracy: Problems of Operationalization", diz que fala-se em déficit democrático porque cada vez mais a representação das mulheres tem sido considerada fator relevante para se analisar as instituições democráticas de um país (2000, p. 92-111).

O corpo político deve representar todos os segmentos existentes na mesma proporção do peso que tais segmentos exercem na formação do corpo social. Esse recorte ressalta o impacto estrutural da desigualdade na esfera pública por conta da marginalização de determinados grupos. Contudo, a teoria democrática clássica não desenhou o mecanismo representativo com o objetivo de criar um espelho da composição da sociedade. Ainda assim, dada a grande dificuldade da maioria das democracias em incorporar segmentos relevantes da sociedade e do eleitorado nos espaços de poder a despeito da igualdade de direito e do sufrágio universal, passou-se a considerar injustas as barreiras enfrentadas por determinados grupos sociais no exercício da política institucional.

A baixa presença das mulheres nos domínios da democracia representativa, desse modo, é encarada como sintoma da limitação da democracia real, que pressupõe uma engenharia política com capacidade para incluir as identidades sociais relevantes de uma população. A adoção de dispositivos políticos específicos para promover a inclusão de membros dos grupos excluídos de âmbitos institucionais, como as amplamente adotadas cotas eleitorais, pode ser interpretada como um reconhecimento dos limites de uma "política de interesses", na qual não importa quem representa, mas o que é representado.

Revista do Direito [ISSN 1982-9957]. Santa Cruz do Sul, v. 2, n. 55, p. 120-135, maio/ago. 2018. https://online.unisc.br/seer/index.php/direito/index 
Mulheres, política e (sub) representação feminina: a ADI 5617 e as ações afirmativas para assegurar a participação feminina mínima nas casas legislativas

Considerando o problema apresentado, isto é, a sub-representação feminina no parlamento brasileiro, bem como a sua relevância sociopolítica e a oportunidade do momento, uma vez que se aproximam as eleições parlamentarem de 2018, o objetivo do presente artigo é, primeiramente, a partir da recaptulização de momentos-chaves históricos, elaborar um panorama do desenvolvimento do direito ao voto feminino no Brasil. Em segundo lugar, adotando-se uma metodologia críticopropositiva, a partir da técnica de pesquisa de levantamento documental - doutrinário, legislativo e judiciário - analisar a atual situação da presença feminina nos cargos eletivos, em especial da existência de cotas partidárias, da ADI 5617, e elencar propostas capazes de, efetivamente, garantir maior participação feminina na política.

\section{BREVE CAPÍTULOS HISTÓRICOS DA LUTA PELO VOTO FEMININO NO BRASIL}

\subsection{Do primeiro voto feminino à criação do Partido Republicano Feminino (PRF)}

A desigualdade política de gênero permeia toda a história brasileira. Nos tempos de Brasil Império, durante a vigência da Constituição de $1824^{3}$ - artigos 90 a 92 - o voto era privilégio de uma pequena camada social, composta essencialmente por homens ricos, maiores de 25 anos. Em 1881, com a inclusão dos artigos $6^{\circ}$ a $9^{\circ}$ na Constituitção Federal, a restrição ao voto foi aumentada de forma a proibir a participação de analfabetos. Desta forma, mulheres, pobres e escravos eram excluídos do processo político, situação que se perdurou até a Velha República.

Mesmo com a Proclamação da República, em 1889, a participação eleitoral continuou restritiva, apesar do abandono do critério censitário. As mulheres, os analfabetos, os mendigos, os militares e os religiosos não tinham direito a voto. A promulgação da Constituição de 1891 ainda fortaleceu a exclusão, pois foi retirada a obrigação de o Estado fornecer educação primária, condição básica para o aumento do eleitorado por meio da educação dos analfabetos pobres. $\mathrm{O}$ argumento para a vedação da participação do analfabeto nas eleições era que seu voto poderia ser facilmente manipulável e corruptível (AVELAR, 2001, p. 16-7) .

Em relação à participação feminina, a proibição ao voto sequer foi abordada na Constituição de 1891, pois era considerada natural a exclusão da mulher, que para tanto não necessitava ser nem mesmo mencionada, apesar de o direito das mulheres ao voto já ser defendido na Assembleia Constituinte por homens como César Zama, Nilo Peçanha, Epitácio Pessoa e Hermes da Fonseca, sem êxito (PINTO, 2003, p. 16).

Nessa época começaram manifestações e lutas de homens e mulheres pelo direito ao voto feminino. Um exemplo é o da cirurgiã dentista Isabel de Souza Matos. Em 1885, ela solicitou o direito ao alistamento eleitoral em função de uma lei que facultava o voto aos detentores de títulos científicos (Lei Saraiva), obtendo sucesso no Rio Grande do Sul, mas não no Rio de Janeiro, quando requereu esse direito em 1890. A advogada Myrthes de Campos e a professora Leolinda Daltro também requereram alistamento eleitoral, porém com o argumento de que a Constituição não vedava o voto

${ }^{3}$ http://www.monarquia.org.br/PDFs/CONSTITUICAODOIMPERIO.pdf Acesso em 03/01/2018. 
feminino, pois a proibição explicita consistia somente aos mendigos, analfabetos, aos praças e os religiosos. Ambos os pedidos foram negados. Como reação a esse fato, Leolinda Daltro e a escritora Gilka Machado lideraram um grupo de mulheres e fundaram, em 23 de dezembro de 1910, o Partido Republicano Feminino (PRF) (PINTO, 2003, p. 16) .

No parágrafo $4^{\circ}$ do estatuto do PRF, depreende-se o inconformismo das fundadoras com a negação do direito ao voto feminino pelos intérpretes da Constituição Republicana de 1891 e a luta para que as mulheres sejam inseridas na sociedade por meio da participação política. De acordo com Celi Pinto (2003, p. 16) a criação de um partido por mulheres que não detinham direitos políticos é significativa e reflete o objetivo de inserir os interesses das mulheres na arena política.

\subsection{A Liga pela Emancipação Intelectual da Mulher, a primeira mulher eleita no Brasil}

O Partido Republicano foi extinto em meados da década de 1910, mas, no mesmo período, a bióloga Bertha Lutz começou a organizar a Liga pela Emancipação Intelectual da Mulher. Lutz era oriunda de família tradicional, pertencente à elite econômica e intelectual nacional, que a proporcionou estudos e formação em biologia na Sorbonne, em Paris, e em Direito em sua volta ao Brasil. Por seu poderio econômico, intelectual e profissional, pois havia passado no concurso público para o cargo de bióloga, tinha trânsito na elite política dominante e acesso a pessoas influentes da época (PINTO, p. 21-3).

A Liga pela Emancipação da Intelectual da Mulher era formada por um pequeno grupo de mulheres da elite burguesa da época. Alves destaca que isso era um trunfo - pois sendo esposas, filhas amigas de homens da classe dominante, tinham acesso aos centros de poder. Em 1922 a Liga sucedida pela Federação Brasileira para o Progresso Feminino (FBPF). As principais ações da FBPF voltavam-se ao direito à educação e ao voto feminino, atuando de forma a promover eventos, como o I Congresso Internacional Feminista, e articulações com parlamentares e instituições para a defesa de matérias legislativas sobre o assunto (ALVES, p. 105).

A partir dessas articulações, Bertha Lutz conheceu Juvenal Lamartine, deputado e membro da Comissão de Constituição e Justiça da Câmara, responsável por analisar um projeto de lei que estendia o direito de voto às mulheres. Após o contato do parlamentar com uma comissão de feministas composta por Lutz e suas aliadas, ele elaborou parecer favorável à aprovação da matéria. O projeto não teve andamento, mas iniciava-se uma parceria política entre Lutz e Lamartine. Em 1927, já como senador e candidato a governador do Rio Grande do Norte, Juvenal Lamartine prometeu que, se eleito, as mulheres norte-rio-grandenses poderiam votar e serem votadas, angariando o apoio maciço de Bertha Lutz e algumas de suas companheiras afiliadas à FBPF (SCHUMAHER, 2000, p. 107).

As feministas realizaram palestras, participaram de eventos públicos de campanha e ainda sobrevoaram a cidade de Natal em um avião monomotor para lançarem panfletos em apoio à eleição de Lamartine, como lembra Shchumaher (2000, p. 217). 
Mulheres, política e (sub) representação feminina: a ADI 5617 e as ações afirmativas para assegurar a participação feminina mínima nas casas legislativas

Eleito, exerceu pressão para que o voto feminino fosse incluído na reforma da Constituição Estadual, promovida pela Assembleia Legislativa na época. Como resultado, o ainda governador do Rio Grande do Norte, José Augusto Bezerra de Medeiros, antecessor de Lamartine, promulgou a Lei Estadual no 660, de 25 de outubro de 1927, cujo art. 77 das Disposições Gerais do Capítulo XII dispõe: -No Rio Grande do Norte poderão votar e ser votados, sem distinção de sexos, todos os cidadãos que reunirem as condições exigidas por esta lei.

Um mês após a edição da Lei, a professora Celina Guimarães Viana, aos 29 anos de idade, torna-se a primeira mulher eleitora na América do Sul. Em 1928, foram realizadas as primeiras eleições com a participação das mulheres no Rio Grande do Norte, que consagrou Alzira Soriano como a primeira prefeita da história da América do Sul, eleita para administração do Município de Lages com $60 \%$ dos votos válidos ${ }^{4}$.

Também em 1928, José Augusto Bezerra de Medeiros foi eleito para senador do Rio Grande do Norte, o que provocou questionamentos acerca da validade dos votos femininos para a eleição de um cargo federal. A Comissão de Poderes do Senado Federal, responsável por analisar o caso, retirou os votos femininos da apuração da eleição, ou seja, José Augusto foi proclamado senador sem a contabilização dos votos de suas eleitoras. Indignadas com a decisão, a FBPM lança a Declaração dos direitos da Mulher, manifesto em defesa da autonomia, independência e igualdade dos direitos da mulher (ALVES, 1980, p. 119; SCHUMAHER, 2000, p. 219).

Já em 1930, a República Velha foi derrotada pela Revolução de Getúlio Vargas, que nomeou uma comissão para tratar da reforma eleitoral. Ao saber que o presidente dessa comissão seria um jurista contrário ao sufrágio feminino universal, as feministas da FBPM foram à luta. A Dra. Carmem Coutinho, aliada de Bertha Lutz, foi apresentada a Getúlio Vargas por intermédio de seu primo. Em entrevista dada à Branca Moreira Alves, Bertha Lutz relata a pressão das feministas em defesa do voto feminino amplo:

Então nós fomos reclamar. O secretário do Getúlio era primo da Carmem Portinho. Então nós tínhamos um meio de agir junto a Getúlio. Mandamos dizer a ele que não queríamos o voto qualificado, queríamos o voto geral. Ele foi apresentado à Carmem pelo Gregório Porto, primo dela. Ele disse: -Dra. Carmem, eu sou a favor das mulheres porque elas fizeram metade da Revolução!ll Ela disse: -É por isso que o Sr. Só quer dar metade do voto?\| -Como metade do voto?\|l Ela disse: -Pois é, quer dar voto qualificado, para certas classes sim, as outras não. Nós não queremos assim. Ou tudo ou nada!ll Ele disse: —Está bem, eu falo com a Comissão para dar tudoll (ALVES, 1980, p. 125).

\subsection{Consolidando o Direito ao Voto: do Código Eleitoral à Constituição de 1988}

\footnotetext{
4 TRIBUNAL REGIONAL ELEITORAL DO RIO GRANDE DO NORTE. Os 80 anos do voto de saias no Brasil. Disponível em: http://www.tre-rn.jus.br/institucional/centro-de-memoria/os-80-anos-do-votode-saias-no-brasil-tre-rn. Acesso em:20 de agosto de 2017.
} 
Em fevereiro de 1932, foi promulgado o Código Eleitoral, estabelecendo o voto secreto, o voto feminino e o cadastramento eleitoral a partir de 18 anos (ALVES, 1980, p. 126). Dessa forma, é errônea a afirmação de que o direito de voto às mulheres foi uma concessão, uma benesse, uma estratégia eficaz de Vargas. Como visto, essa conquista baseia-se em mais de trinta anos de manifestações e lutas a favor da participação política das mulheres. Contudo, havia diferença entre o sufrágio feminino e o masculino quanto à obrigatoriedade do voto: o voto era obrigatório para todos os homens e para as mulheres detentoras de funções públicas remuneradas.

Portanto, para a maioria da população feminina o voto era facultativo (BITHIAH, 2012, p. 545) . A FBPF continuou a pressão por maior participação política das mulheres, dessa vez para serem representadas por Bertha Lutz na Comissão responsável por elaborar o anteprojeto da nova Constituição. Foi publicado um memorial com aproximadamente cinco mil assinaturas em apoio à nomeação de Lutz para a Comissão, solicitação atendida por Getúlio Vargas, o qual ainda nomeou outra mulher, Nathércia Silveira (ALVES, 1980, p. 126). Finalmente, nas eleições da Assembleia Constituinte de 1933 as mulheres puderam, de fato, serem eleitoras e candidatas. Nesse momento, Bertha Lutz se candidatou pelo Partido Autonomista, porém foi vítima de difamação pela imprensa sob acusação de fraude eleitoral, alegação que posteriormente se mostrou falsa.

Mas mesmo assim, a bióloga não se elegeu. Todavia, uma mulher foi eleita para a Assembleia Constituinte: Carlota Queiróz foi a primeira deputada federal do Brasil. A médica, oriunda de família tradicional paulistana, conseguiu entrar na esfera política devido à organização de um grupo de setecentas mulheres para prestar assistência aos feridos da Revolução Constitucionalista de 1932, movimento promovido pelo Estado de São Paulo contra o governo provisório de Getúlio Vargas. Sua atitude teve grande visibilidade e seu nome foi indicado para compor a Chapa Única por São Paulo Unido (SCHUMAHER, 2000, p. 129) .

Em 1934, foram realizadas novas eleições, sendo reeleita Carlota Queiróz, para deputada federal, e eleitas nove deputadas estaduais, sendo sete delas integrantes da FBPM. Novamente, Bertha Lutz não foi eleita, mas conseguiu a primeira suplência da vaga do deputado federal Cândido Pessoa, que faleceu em 1936. No mesmo ano em que Bertha Lutz assumiu a vaga de deputada federal, a FBPM promoveu o III Congresso Nacional Feminista, com o objetivo de discutir os rumos da Federação e elaborar as diretrizes de atuação parlamentar.

Lutz chegou a apresentar projetos voltados a mulher, como o Estatuto da Mulher, que propunha a reforma da legislação relativa ao trabalho feminino, e a criação do Departamento da Nacional da Mulher, com o objetivo de consistir em espaço de atuação exclusivamente votado para o atendimento das questões cotidianas das mulheres, como a saúde e a maternidade, e também como um órgão de defesa das condições de trabalho e de vida da população feminina (SCHUMAHER, 2000, p. 111).

Porém, este último projeto sofreu resistências por parte de Carlota de Queirós, que se posicionou contra a ideia de que os cargos do Departamento fossem preenchidos apenas por 
Mulheres, política e (sub) representação feminina: a ADI 5617 e as ações afirmativas para assegurar a participação feminina

mulheres, por acreditar que a proposta era sexista. A decretação do Estado Novo em 1937 encerrou a carreira parlamentar dessas grandes mulheres. Era início de um regime autoritário, marcado pelo o fechamento do Congresso e participação política de uma minoria, fazendo com que as conquistas da Constituição de 1936, inclusive o sufrágio feminino, ficassem apenas no papel.

Com o fim do Estado Novo a democracia é retomada e o voto feminino é plenamente exercido nas eleições para a Assembleia Constituinte de 1946. Mulheres são eleitas para Assembleias Estaduais e Câmaras Municipais, mas nenhuma é eleita para o Congresso Nacional, apesar de terem concorrido dezoito candidatas Ou seja, a Constituição de 1946 foi elaborada somente por homens. O direito ao voto feminino foi reconhecido na nova Carta Magna, porém a edição do Código Eleitoral, em 1950, ainda manteve o a distinção entre homens e mulheres quanto à obrigatoriedade do voto, o que pode ser entendido como discriminação contra setores da população feminina (BITHIAH, 2012, p.. 59).

Entre 1946 e 1964 somente três mulheres conseguiram ser eleitas para o Congresso Nacional: Ivette Vargas (PTB-SP), Nita Costa (PTB-BA) e Necy Novaes (PTB-BA). Durante o Golpe Militar de 1964 e a edição do Ato Institucional no 2, que implantou o bipartidarismo, as deputadas federais Ivette Vargas e Necy Novaes, únicas representantes femininas na ocasião, se filiaram respectivamente ao MDB e à Arena(BITHIAH, 2012, p. 81-2).

Nas eleições de 1966, seis mulheres foram eleitas deputadas federais, sendo que três delas concorreram ao pleito após as cassações dos mandatos dos seus cônjuges. Dessas seis parlamentares, cinco tiveram seus mandatos cassados pelo regime militar em 1969, todas do MDB: Ivette Vargas, Lígia Doutel de Andrade, Maria Lucia Mello de Araújo, Júlia Steinbruch e Nysia Carone. A única deputada da Arena concluiu seu mandato em 1971 e foi reeleita para o período 1971-1975, sem reeleger-se nos demais pleitos. Nas eleições para o período de 1975 a 1979, somente uma mulher foi eleita deputada federal: Lygia Lessa Bastos, pelo Arena.

Porém, as atividades de comemoração do Ano Internacional da Mulher, em 1975, promovido pela ONU, impulsionaram movimentos sociais e feministas no Brasil na luta por seus direitos. $\mathrm{Na}$ época, o País era governado por Ernesto Geisel, que já prometia uma distensão política gradual e controlada (PINTO, 2003, p. 56).

Em 1978, quatro mulheres foram eleitas, três do MDB e uma da Arena. E em 1979, pela primeira vez na história do Brasil, uma mulher tornou-se senadora: Eunice Michilles ocupou o cargo em virtude de falecimento do titular da vaga. Em 1979, foi aprovada a Lei da Anistia, que marcou o início de uma época de maior liberalização, menor repressão e o fim do bipartidarismo. Em 1982, foram realizadas as eleições para o Congresso Nacional e a primeira eleição direta para governadores estaduais desde o Golpe Militar. Oito mulheres tornaram-se deputadas federais, representando quatro diferentes partidos (BITHIAH, 2012, p. 118).

$\mathrm{Na}$ década de 1980, foram criadas importantes entidades voltadas à mulher no Brasil e no mundo. Alguns exemplos são os conselhos estaduais da condição feminina (MG e SP), para traçar 
políticas públicas para as mulheres; a primeira Delegacia de Atendimento Especializado à Mulher (Deam), em São Paulo; o Fundo de Desenvolvimento das Nações Unidas para a Mulher (Unifem), em lugar do antigo Fundo de Contribuições Voluntárias das Nações Unidas para a Década da Mulher; Departamento Nacional para Assuntos da Mulher, criado pela Central Geral dos Trabalhadores (CGT) e o Conselho Nacional dos Direitos da Mulher (CNDM), órgão que teve fundamental importância na participação das mulheres na redemocratização do País.

Para a legislatura de 1987 a 1991, foram eleitas 29 mulheres ao cargo de deputadas federais. Essas parlamentares, embora com características discrepantes entre si, conseguiram se unir em prol dos interesses das mulheres durante sua participação na Assembleia Constituinte, se autodenominando bancada feminina (BITHIAH, 2012, p. 127-30).

A legislatura de 1991-1995 foi marcada pelo processo de impeachment do presidente Fernando Collor e pela criação de duas CPIs sobre questões femininas: a CPI da Violência Contra a Mulher e a CPI Sobre a Esterilização em Massa de Mulheres no Brasil. Em 1995, entrou em vigor no País a Convenção sobre a Eliminação de Todas as Formas de Discriminação contra a Mulher. Para essa legislatura, foram eleitas 30 deputadas federais. Para o período de 1995-1999, foram eleitas 37 deputadas.

A constatação de que, em geral, as mulheres detinham menos de $10 \%$ dos cargos na Câmara dos Deputados, no Senado Federal, nas prefeituras brasileiras e nas câmaras de vereadores, fez com que fosse buscada uma maior presença feminina na política (BITHIAH, 2012, p. 189-91). Para isso, foi criada a cota para as mulheres nas candidaturas parlamentares, tema melhor abordado no próximo capítulo.

\section{O ATUAL CENÁRIO BRASILEIRO}

Embora sejam a maioria da população brasileira, segundo dados do IBGE$^{5}$, maioria do eleitorado, a maioria do eleitorado, segundo $\mathrm{TSE}^{6}$, a presença feminina nas Casas Legislativas não chega nem próximo aos percentuais indicados: alcançaram apenas 9,94\% das vagas na Câmara dos Deputados e 13,58\% no Senado nas eleições de $2014^{7}$, segundo TSE. De acordo com o ranking sobre o percentual de mulheres nas Casas Legislativas realizado pelo Interparlamentary Union, com dados atualizados até $1^{0}$ de novembro de 2016, dos 193 países listados, o Brasil ocupa a 154 posição atrás inclusive, de países como o Afeganistão.

O resultado nas Eleições Municipais de 2016 mantém esse baixo percentual de mulheres eleitas, e chama atenção pelo elevado número de mulheres candidatas em todo território nacional

5https://brasilemsintese.ibge.gov.br/populacao/distribuicao-da-populacao-por-sexo.html Acesso em 03/03/2018.

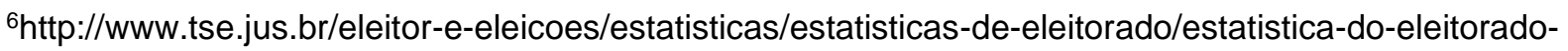
por-sexo-e-faixa-etaria Acesso em 03/03/2018.

${ }^{7} \mathrm{http}: / /$ www.tse.jus.br/eleitor-e-eleicoes/estatisticas/eleicoes/eleicoes-anteriores/estatisticas-

candidaturas-2014/estatisticas-eleitorais-2014-resultados Acesso em 03/03/2018

Revista do Direito [ISSN 1982-9957]. Santa Cruz do Sul, v. 2, n. 55, p. 120-135, maio/ago. 2018. https://online.unisc.br/seer/index.php/direito/index 
Mulheres, política e (sub) representação feminina: a ADI 5617 e as ações afirmativas para assegurar a participação feminina

que não obtiveram voto algum - nem mesmo o seu próprio. Em números gerais, em 2016 apenas $14 \%$ dos vereadores eleitos eram mulheres, apesar de elas serem $31 \%$ dos candidatos aptos nesse pleito. Dentre as capitais, verificou-se que em 10 deles houve um aumento do número de mulheres eleitas, em 13 uma diminuição, e em 3 não houve alteração ${ }^{8}$

A respeito da importância da participação da mulher na política para o fortalecimento da democracia, a agência Patrícia Galvão publicou uma pesquisa realizada pelo IBOPE com os seguintes dados ${ }^{9}$ :

i. $\quad 71 \%$ dos entrevistados consideram a reforma política muito importante/ importante para garantir $50 \%$ de homens e $50 \%$ de mulheres nas listas de candidaturas dos partidos.

ii. $74 \%$ dos entrevistados acreditam que só há democracia de fato com a presença de mais mulheres nos espaços de poder e de tomada de decisão.

iii. $78 \%$ concordam que os partidos deveriam apresentar uma lista de candidatos composta por metade de homens e metade de mulheres.

iv. 8 em cada 10 entrevistados consideram que, sendo as mulheres hoje mais da metade da população, deveria ser obrigatória a participação de metade de mulheres e metade de homens nas Câmaras de Vereadores, Assembleias Legislativas Estaduais e no Congresso Nacional.

Na mesma linha, a Procuradoria da Mulher ${ }^{10}$, no Senado Federal, realizou uma pesquisa pelo DataSenado, entre agosto e setembro de 2014, questionando o eleitor sobre intensão de voto e gênero, e os resultados indicam que a baixa representatividade feminina na política não está relacionada, a rigor, a preconceito de gênero por parte do eleitorado:

i. $83 \%$ responderam que na hora de escolher alguém para votar, o sexo do candidato não faz diferença;

ii. ii. $79 \%$ já votaram em candidatas mulheres;

iii. iii. $62 \%$ das mulheres entrevistadas responderam que se candidatariam se acreditassem ter chances de serem eleitas;

iv. iv. $41 \%$ das mulheres e $36 \%$ dos homens responderam que o principal motivo que leva uma mulher a NÃO se candidatar para um cargo político é a falta de apoio dos Partidos.

\footnotetext{
8 http://www.tse.jus.br/eleitor-e-eleicoes/estatisticas/eleicoes/eleicoes-anteriores/estatisticas-eleitorais2016/resultados Acesso em 03/03/2018.

9 Pesquisa Ibope / Instituto Patrícia Galvão 2013. Mais Mulheres na política. Base: amostra (2.002). Disponível em: http://agenciapatriciagalvao.org.br/wpcontent/uploads/2013/07/mais_mulheres_politica.pdf. Acesso em: 17/04/2017.

10 Procuradoria Especial da Mulher/ DataSenado. 2014. Pesquisa DataSenado. Mulheres na Política. Base: amostra (1091). Disponível em: < http://www12.senado.gov.br/institucional/procuradoria/procpublicacoes/cartilha-mulheres-na-politica>. Acesso em: 17/04/2017.
} 


\section{POLÍTICA DE COTAS NO BRASIL}

A Lei 9.096/1995, que disciplinou pela primeira vez em nosso ordenamento a cota de gênero em eleições proporcionais impôs algumas iniciativas no intuito de promover a participação da mulher na política, são elas:

i. Cota de $30 \%$ por gênero na lista de candidatos apresentados pelos partidos políticos ou coligações.

ii. Reserva de tempo de propaganda partidária para a promoção da participação das mulheres na política

iii. Utilização de no mínimo $5 \%$ das verbas recebidas pelo Fundo Partidário em programas de promoção e difusão da participação política das mulheres (artigo 44, V, Lei no 9096/95) iv. Direcionamento do percentual mínimo de 5\% e máximo de $15 \%$ do montante do Fundo Partidário ao financiamento de campanhas eleitorais de suas candidatas incluídos nesse valor ainda a criação e manutenção de programas de difusão da participação feminina na política.

A despeito da adoção destas medidas, o impacto em termos de conversão do número de mulheres candidatas em mulheres eleitas é muito baixo. Apesar da previsão de cotas de gênero na lista de candidatos dos partidos datar de 1997, não é possível identificar mudanças significativas na representação feminina na política antes e depois da implementação das contas. Destaca-se, novamente, que a exigência legal das cotas de gênero nas listas de candidatos foi inserida no ordenamento jurídico brasileiro em 1997 para as eleições gerais, e o que se identifica é, na verdade, uma queda de representatividade entre o pleito de 1994 e 1998: de 6,23\% para 5,65\%, com a implementação das cotas.

A alteração do art. 10, $3^{\circ}$ da Lei das Eleições que levou à virada da jurisprudência na interpretação sobre a forma de respeitar o percentual mínimo - em vista da quantidade de candidatos que poderiam ser apresentados ou da quantidade de candidatos efetivamente apresentados pelos partidos - ocorreu em 2009. Interessante notar que em 2010 houve, tal qual 1998, queda de representação feminina: de $8,77 \%$ de mulheres na Câmara dos Deputados passou-se à $8,54 \%$ em 2010.

Nem mesmo para as eleições realizadas em 2014 o impacto foi significativo: a participação feminina passou para 9,94\% dos membros da Câmara dos Deputados. A bem da verdade, tem-se que entre a representação obtida no pleito de 1990 - em que não havia nenhum mecanismo oficial de apoio à candidatura feminina - e no pleito de 2014 - com a exigência legal de reserva mínima de $30 \%$ para apresentação de candidatos por gênero sob pena de indeferimento do DRAP (Demonstrativo de Regularidade de Atos Partidários) do partido/coligação - a variação é de meros 3,98\% (em 1990 5,96\% dos eleitos para a Câmara dos Deputados eram mulheres, e em 2014 esse índice subiu para 9,94\%).

Revista do Direito [ISSN 1982-9957]. Santa Cruz do Sul, v. 2, n. 55, p. 120-135, maio/ago. 2018. https://online.unisc.br/seer/index.php/direito/index 
Mulheres, política e (sub) representação feminina: a ADI 5617 e as ações afirmativas para assegurar a participação feminina mínima nas casas legislativas

Outra evidência de como as práticas dos partidos não amparam as mulheres está na distribuição do dinheiro para as campanhas eleitorais. No gráfico abaixo, há uma comparação entre a média de recursos destinados por cada partido a seus candidatos do sexo masculino $\mathrm{X}$ feminino. Assim, se o valor é próximo de 1, significa que o partido não diferencia homens e mulheres na distribuição de dinheiro. Se a razão fica acima de 1, quer dizer que as mulheres são favorecidas; para os valores abaixo de 1 , os homens levam vantagem na repartição feita pelo partido ${ }^{11}$.

Analisando o gráfico abaixo, percebe-se que, em geral os partidos brasileiros destinam menos recursos para suas candidatas do que para seus pares do sexo masculino. Entre os partidos que mais discriminam a distribuição de recursos entre homens e mulheres, não há distinção ideológica, cabe tanto partidos de esquerda, quanto de direita.

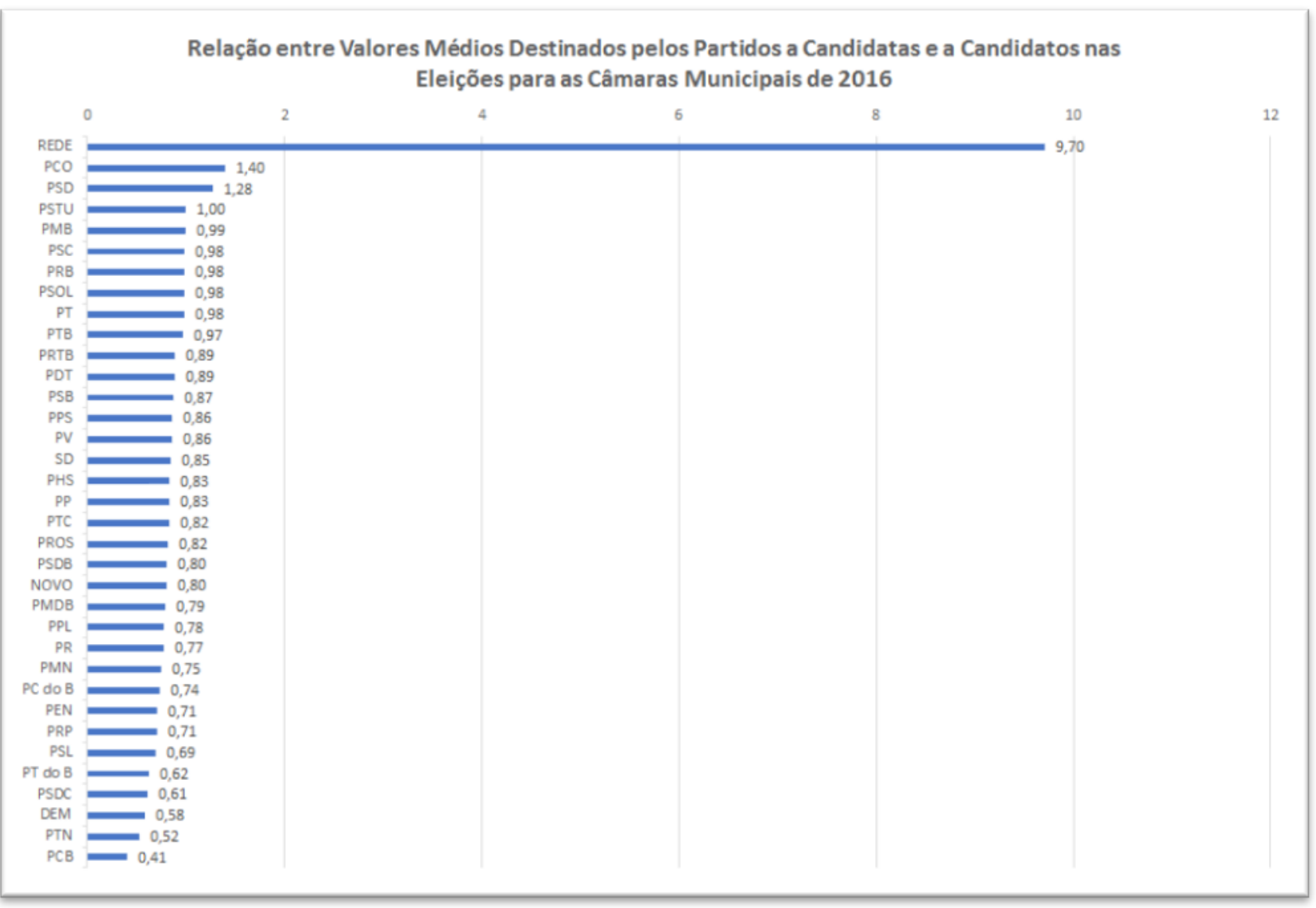

FONTE: http://www.politize.com.br/participacao-das-mulheres-na-politica-brasileira/ Acesso em 20/08/2017.

Em que pese a desigualdade de gênero que prevalece no Brasil, muitos países tem aprovado reformas corajosas para estimular a competitividade das mulheres nas disputas eleitorais. Eleições com um percentual elevado de cadeiras exclusivas para mulheres, cotas no financiamento público de campanha e estímulos para os partidos admitirem mais mulheres em sua estrutura decisória são

11 http://www.politize.com.br/participacao-das-mulheres-na-politica-brasileira/ Acesso em 20/08/2017

Revista do Direito [ISSN 1982-9957]. Santa Cruz do Sul, v. 2, n. 55, p. 120-135, maio/ago. 2018. https://online.unisc.br/seer/index.php/direito/index 
algumas das medidas que vem sendo adotadas em diversos países para estimular a participação feminina na política.

\section{A ADI 5617}

A pedido do vice-procurador-geral eleitoral, Nicolao Dino, e do procurador regional eleitoral em Minas Gerais, Patrick Salgado Martins, foi proposta pelo então Procurador Geral da República, Rodrigo Janot, a Ação Direta de Inconstitucionalidade (ADI) 5617, pleiteando a concessão de liminar para suspender os efeitos do art. 9o da Lei 13.165/2015 e, no mérito, declarar inconstitucionais os limites máximo e mínimo impostos para o financiamento das campanhas de candidatas do sexo feminimo.

A norma, objeto da ação é a seguinte:

Art. 9 ○ Nas três eleições que se seguirem à publicação desta Lei, os partidos reservarão, em contas bancárias específicas para este fim, no mínimo $5 \%$ e no máximo $15 \%$ do montante do Fundo Partidário destinado ao financiamento das campanhas eleitorais para aplicação nas campanhas de suas candidatas, incluídos nesse valor os recursos a que se refere 0 inciso V do art. 44 da Lei n o 9.096, de 19 de setembro de 1995.

A ADI tem como fundamentação a contrariedade ao princípio fundamental da igualdade (art. 5 o , I), deixa de proteger suficientemente o pluralismo político, a cidadania e o princípio democrático, garantidos no art. 10 , II, V e parágrafo único, falha no atingimento do objetivo fundamental de construir sociedade livre, justa e solidária, disposto no art. 3o , I, além de ferir os princípios da eficiência e da finalidade (art. 37) a autonomia dos partidos políticos (art. 17, § 10), todos da Constituição da República. ${ }^{12}$

Aliás, merece especial atenção o fundamento, sustentáculo da ação:

INCONSTITUCIONALIDADE DE PERCENTUAL MÁXIMO DO FUNDO PARTIDÁRIO PARA FINANCIAMENTO DE CANDIDATAS A falta de recursos foi uma das razões identificadas para a pouca efetividade das cotas e que pautou a reforma eleitoral expressa na Lei 13.165/2015. Vagas reservadas sem correspondente alocação de recursos de campanha tornavam-se pouco efetivas, verdadeira quimera. Recente matéria produzida pela representa- ção da Organização das Nações Unidas (ONU) no Brasil registrou, com razão, que "relatório da IPU [Inter-Parliamentary Union] também enfatizou a necessidade de acabar com os impedimentos para a candidatura de mulheres, como a falta de financiamento adequado para campanhas, e reiterou o papel importante dos partidos políticos na mudança do status quo. A aprovação da norma legal almejaria corrigir esse cenário, com reserva de frações do fundo partidário para candidatas, de forma a aumentar as possibilidades de mulheres lançarem candidaturas com chances reais de êxito. A fixação de limite máximo do montante do fundo partidá- rio a ser reservado para campanhas de mulheres, na norma atacada, todavia, não apenas viola o princípio da igualdade, como, ainda mais grave, inverte o sistema de cotas eleitorais."

${ }^{12}$ http://www.mpf.mp.br/pgr/documentos/adi-5617.pdf. Acesso em 20/08/2017 
Ainda dentro da $\mathrm{ADI}^{13}$ sobre a desigualdade de gênero na política e as ações afirmativas tendentes a minorá-la, cabe resgatar observações da Ministra Carmen Lúcia, desconstruindo imputações de inconstitucionalidade da cota de gênero em eleições proporcionais:

Tem-se, assim, que o assombro admirativo com que reagiram os homens apenas demonstra, inequivocadamente, o preconceito que continua a prevalecer na sociedade em relação à mulher e, assim, a necessidade de se aplicar o princípio da igualdade com mais democracia e justiça do que a concepção tradicional, acanhada e formal, fazia nele conter. Não se vislumbra inconstitucionalidade manifesta, nem sequer novidade, na norma do art. 11, § 3 o , da Lei no 9.110/96. E se mais não tiver de positivo, tem a possibilidade de estampar preconceitos que se afirmam inexistentes mesmo por figuras masculinas respeitadas, admiradas e reconhecidas pela defesa dos direitos iguais de todos. É apenas um vício esse preconceito, tatuado, de tal maneira arraigado na história das sociedades, que nem quem lhe traz à alma o reconhece às vezes (ROCHA, 1996, p. 86).

O texto em comento foi publicado em 1996, apenas um ano após edição da Lei 9.096/1995, que disciplinou pela primeira vez em nosso ordenamento a cota de gênero em eleições proporcionais. Duas décadas depois, a crítica permanece atual: não apenas continuam sendo necessárias ações afirmativas para assegurar participação feminina mínima nas casas legislativas, como ainda se enfrentam obstáculos no próprio processo de estabelecimento dessas políticas sociais ${ }^{14}$.

\section{CONSIDERAÇÕES FINAIS}

A sub-representação das mulheres é um sintoma do déficit democrático presente em diversos regimes eletivos. Falamos em déficit democrático pois, considerando o princípio da representação descritiva, uma assembleia legislativa só é considerada representativa se sua composição for uma reprodução reduzida da sociedade. Assim, podemos dizer que existe um déficit de representação em Estados nos quais não existe paridade entre os sexos nas casas legislativas.

As regras eleitorais infuenciam diretamente as chances das candidaturas femininas. Concluímos também que a forma como a sociedade se organiza materialmente e a cultura têm peso no processo de inclusão feminina nas assembleias legislativas. A política é uma arena predominantemente masculinam que se reflete no baixo índice de participação das mulheres nesse espaço e reproduz uma situação de marginalização.

As desigualdades entre os sexos são perpetuadas por mecanismos sutis de dominação, que naturalizam e legitimam as diferenças incorporadas desde a mais tenra infância que pré-moldam oportunidades e proibições de acordo com condições objetivas. A despeito do desenvolvimento de uma cultura mais igualitária, as práticas ainda são exercidas de forma bastante tradicional e certas desigualdades não são percebidas como injustas.

Em parecer técnico apresentado dia 20/11/2016, a advogada e especialista em Direito Eleitoral, Pollyanna Santos argumenta que é essencial a adoção de políticas públicas que possam

${ }^{13}$ http://www.mpf.mp.br/pgr/documentos/adi-5617.pdf. Acesso em 20/08/2017

14 http://www.mpf.mp.br/pgr/documentos/adi-5617.pdf. Acesso em 20/08/2017 
repercutir de fato na conversão do número de mulheres candidatas em mulheres eleitas, conforme se demostrou. Neste documento foram apresentadas propostas com essa finalidade precípua, abaixo relacionadas:

a) Regulamentação de Sistema de Cotas de Representação por meio de reserva de cadeiras no Poder Legislativo, para os cargos obtidos pelo Sistema Proporcional e Majoritário, observadas as suas especificidades;

b) Regulamentação no âmbito intrapartidário no sentido de facilitar o ingresso das mulheres na vida política, entre os quais: adoção de cotas para os dirigentes partidários, distribuição proporcional de tempo de propaganda eleitoral e verbas para financiamento de campanha entre os gêneros e maior fiscalização dos partidos no cumprimento das regras já existentes (tempo de propaganda partidária e utilização de verbas do Fundo Partidário);

c) Reserva de tempo de propaganda eleitoral para as candidatas mulheres, de forma proporcional ao mínimo de candidaturas por gênero legalmente estabelecido;

d) Reserva de verbas partidárias para as candidatas mulheres, de forma proporcional ao mínimo de candidaturas por gênero legalmente estabelecido;

e) Modificação dos requisitos para distribuição das verbas do Fundo Partidário aos Partidos, inserindo como parâmetro legal para a distribuição do FP o número de mulheres eleitas pelos Partidos Políticos.

Enquanto são assegurados $30 \%$ de vagas para candidatas mulheres, verifica-se, que entre os anos 2002 e 2014 o percentual de mulheres eleitas para o Senado não chega a 10\%. O mero estabelecimento de cotas para candidatas por lei no modelo brasileiro não tem gerado efeitos significativos no aumento da participação política feminina. Partindo dessa constatação, verifica-se a importância de discutir outras propostas e formatos, como o caso da reserva de cadeiras. Essa proposta, diferentemente do percentual mínimo de mulheres nas listas de candidatos, assegura que efetivamente os percentuais exigidos pela lei sejam convertidos em mulheres eleitas e ocupando cargos de tomada de decisão.

A reserva de vagas não viola o princípio democrático, como procuramos destacar. Não prejudica a representatividade decorrente do voto, uma vez que será mantida a representação partidária. Isso porque a substituição dos candidatos em atenção ao percentual mínimo por sexo será realizada no âmbito do partido que logrou obter representação político partidário por meio do voto, com a devida consideração dos cálculos de quociente eleitoral e partidário.

\section{REFERÊNCIAS}

Revista do Direito [ISSN 1982-9957]. Santa Cruz do Sul, v. 2, n. 55, p. 120-135, maio/ago. 2018. https://online.unisc.br/seer/index.php/direito/index 
Mulheres, política e (sub) representação feminina: a ADI 5617 e as ações afirmativas para assegurar a participação feminina

ALVES, Branca Moreira. Ideologia e feminismo: a luta da mulher pelo voto no Brasil. Petrópolis: Vozes, 1980.

AVELAR, Lúcia. Mulheres na elite política brasileira. 2. ed. São Paulo: Fundação Konrad Adenauer/UNESP, 2001.

BITHIAH, Débora; RABAT, Márcio. Palavra de mulher: oito décadas de direito de voto. Brasília: Câmara dos Deputados, 2012.

MINISTÉRIO PÚBLICO FEDERAL. Disponível em: <http://www.mpf.mp.br/pgr/documentos/adi5617.pdf>. Acesso em 20/08/2017.

PAXTON, Pamela. Women's Suffrage in the Measurement of Democracy: Problems of Operationalization Studies in Comparative International Development, Fall 2000, Vol. 35.

Instituto Patrícia Galvão 2013. Mais Mulheres na política. Base: amostra (2.002). Disponível em: http://agenciapatriciagalvao.org.br/wpcontent/uploads/2013/07/mais_mulheres_politica.pdf Acesso em: 17/08/2017.

PINTO, Celi Regina Jardim. Uma história do feminismo no Brasil. São Paulo: Perseu Abramo: 2003.

Participação das mulheres na política brasileira http://www.politize.com.br/participacao-das-mulheresna-politica-brasileira/. Acesso em 20/08/2017.

Procuradoria Especial da Mulher/ DataSenado. 2014. Pesquisa DataSenado. Mulheres na Política. Base: amostra (1091). Disponível em:

http://www12.senado.gov.br/institucional/procuradoria/procpublicacoes/cartilha-mulheres-na-politica Acesso em: 17/08/2017.

ROCHA, Cármen Lúcia Antunes. Ação afirmativa: o conteúdo democrático do princípio da igualdade jurídica. Revista trimestral de Direito Público, São Paulo, n. 15, 1996.

SANTOS, Polianna Pereira dos. Participação da mulher na Política - Proposições e justificativas. Análise do quadro atual e proposições para a promoção do aumento da participação das mulheres na política

https://www.academia.edu/30575572/Participa\%C3\%A7\%C3\%A3o_da_mulher_na_pol\%C3\%ADtica Acesso em 20/08/2017.

SCHUMAHER, Schuma; BRASIL, Érico Vital: Dicionário mulheres do Brasil: de 1500 até a atualidade. Rio de Janeiro: Zahar, 2000.

SORJ, B. Percepções sobre esferas separadas de gênero. In: Gênero, família e trabalho no Brasil. Rio de Janeiro: Editora FGV, 2005.

TRIBUNAL REGIONAL ELEITORAL DO RIO GRANDE DO NORTE. Os 80 anos do voto de saias no Brasil. Disponível em: http://www.tre-rn.jus.br/o-tre/centro-de-memoria/os-80-anos-do-voto-desaias-no-brasil-tre-rn Acesso em: 15 abr. 2017.

TRIBUNAL SUPERIOR ELEITORAL: http://www.tse.jus.br/eleitor-eeleicoes/estatisticas/eleicoes/eleicoes-anteriores/estatisticas-eleitorais-2016/resultados Acesso em 03/03/2018. 


\section{COMO CITAR ESSE DOCUMENTO:}

BAMBIRRA, Felipe Magalhaes; MARQUES, Milene de Souza. Mulheres, política e (sub) representação feminina: a ADI 5617 e as ações afirmativas para assegurar a participação feminina mínima nas casas legislativas. Revista do Direito, Santa Cruz do Sul, v. 2, n. 55, set. 2018. ISSN 1982-9957. Disponível em: <https://online.unisc.br/seer/index.php/direito/article/view/12080>. Acesso em: doi:https://doi.org/10.17058/rdunisc.v2i55.12080. 